\title{
Obstetrics ICU admissions: learning objectives
}

\author{
Preetkamal, Ripan Bala*, Simranjeet Kaur, Madhu Nagpal
}

Department of Obstetrics and Gynecology, Sri Guru Ram Das University of Health Sciences, Amritsar, Punjab, India

Received: 28 February 2019

Accepted: 07 March 2019

\section{*Correspondence:}

Dr. Ripan Bala,

E-mail: ripanchanana@yahoo.co.in

Copyright: ( $\odot$ the author(s), publisher and licensee Medip Academy. This is an open-access article distributed under the terms of the Creative Commons Attribution Non-Commercial License, which permits unrestricted non-commercial use, distribution, and reproduction in any medium, provided the original work is properly cited.

\section{ABSTRACT}

Background: The management of critical illness in pregnancy requires intensive monitoring of obstetric patients in the intensive care unit. Systematic way of surveillance will allow the measurement of outcomes of interest and associated risk factors. Intensive care unit is highly specified and sophisticated area of hospital which is specifically designed, staffed, furnished and equipped, dedicated to the management of critically sick patients, injuries or complications. The aim of this study was to know the frequency of ICU admission in obstetrical patients, to analyse the medical or surgical comorbidity related to obstetrical problems, to segregate the cause of morbidity and to identify the risk reducing strategies.

Methods: This observational study was conducted in 40 ICU patients in present institute from $1^{\text {st }}$ December 2016 to $28^{\text {th }}$ February 2019. The present study was divided into two groups in group I, intervention was done first followed by ICU intervention and in group II, ICU stabilization was done first followed by obstetrical intervention. The parameters noted were age, parity, gestation age, diagnosis on admission, associated medical and surgical comorbidity, reason for ICU admission, any surgical procedure performed, details of treatment given in ICU like ventilator support, blood transfusion, dialysis or ionotropic support. Patients outcome, review of mortality and area of improvement were also noted.

Results: There were $17.5 \%$ mortalities observed in present study. The most common ICU intervention was blood transfusion $(81.19 \%)$ followed by mechanical ventilation $(37.8 \%)$. Commonest cause of mortality was multiorgan dysfunction $(28.5 \%)$ followed by hypertensive disorder of pregnancy $(14.3 \%)$, peripartum cardiomyopathy $(14.3 \%)$, acute fatty liver of pregnancy (14.3\%), septic shock (14.3\%) and acute febrile illness (14.3\%). Most of the patients were unbooked $(74.3 \%), 47.2 \%$ cases did not receive antenatal care.

Conclusions: There is need for antenatal registration of all pregnant women and institutional deliveries should be the aim. There should be antenatal detection and management of medical and surgical comorbidities. There is need for training in emergency obstetrics so that complication can be recognized and managed at an optimum time.

Keywords: Comorbidities, Intensive care unit, Monitoring, Obstetrics

\section{INTRODUCTION}

Critical illness in pregnancy as a morbidity outcome is difficult to define, hence needs to be measured and studied precisely. As stated by Harmer, "Death represents the tip of morbidity iceberg, the size of which is unknown". ${ }^{1}$ Critical illness can be considered as impending, developing or established significant organ dysfunction, which may lead to long term morbidity or death. The management of critically ill obstetric patients involve intensive monitoring and physiologic support for patients with life threatening but potentially reversible condition. Evaluation of obstetric admission to intensive care units (ICUs) is best way to do surveillance of critical illness in pregnancy. The percentage of obstetric population requiring admission to ICU in developing 
countries ranges from $0.13-4.6 \% .^{2}$ The mortality in these patients ranges from $2.0-43.63 \%$ in developing countries. $^{3}$

In India current maternal mortality ratio is 130 per 100000 live births. The obstetric ICUs are dedicated to manage only obstetric patients having critical obstetrical or medical or surgical complications, managed by staff oriented for obstetric physiology and pathology. There are four levels of critical care defined by intensive care society:

- Level 0: Where needs can be met through normal ward care.

- Level 1: At risk of their condition deteriorating, needing a higher level of observation or those recently relocated from higher levels of care.

- Level 2: Requiring invasive monitoring/intervention include support for single failing organ system (excluding advanced respiratory support).

- Level 3: Requiring advanced respiratory support (mechanical ventilation) alone or basic respiratory support along with support of at least one additional organ.

Critical care in pregnancy poses a major challenge to clinician as it requires consideration of physiological changes associated with pregnancy and the need to reassure the wellbeing of the fetus. ${ }^{4}$

Hypertensive disorders and obstetric haemorrhage are two commonest risk factors for ICU admissions. ${ }^{5}$ The other risk factors are sepsis, abortions, IUFD, acute fatty liver of pregnancy, peripartum cardiomyopathy, amniotic fluid embolism.

There can be certain medical causes, associated with pregnancy that require ICU admission like, pneumonia, acute pyrexia, heart disease, haematological disorders, diabetes mellitus, renal failure, drug abuse etc.

The monitoring and management in ICU include immediate critical assessment and resuscitation. The maternal parameters recorded at least hourly in acute phase of illness include temperature, blood pressure, heart rate, respiratory rate, urine output and transcutaneous oxygen saturation.

Special monitoring includes recording invasive blood pressure, central venous pressure monitoring, acid base balance, end tidal carbondioxide $\left(\mathrm{EtCo}_{2}\right)$ and plateau pressures.

The aim and objectives were to know the incidence of patients requiring critical care during study period from $1^{\text {st }}$ December 2016 to $28^{\text {th }}$ February 2019; to analyse the disease ailment/comorbidity related to medical and obstetric problems; to segregate direct/indirect cause of morbidity and to identify and adapt risk reduction strategies as prime learning objectives.

\section{METHODS}

This observational study was conducted in the Department of Obstetrics and Gynaecology at Sri Guru Ram Das Institute of Medical Sciences and Research, Amritsar.

The subjects included were admitted to emergency/OPD or shifted from OT to ICU between $1^{\text {st }}$ December 2016 to $28^{\text {th }}$ February 2019. The patients were evaluated and categorized in two groups.

\section{Group 1}

In which after optimising obstetrical intervention, the patients were shifted to critical care unit in joint approach with anaesthesiologist as well as other specialities involved in ICU. So, intervention preceded ICU admission.

\section{Group 2}

Where medical/surgical morbidities required need of critical care unit to stabilize the patient first and then optimal obstetrical intervention was done.

The parameters noted were age, parity, diagnosis on admission, associated medical and surgical condition, any surgical procedures performed, details of treatment given in ICU like ventilator support, blood and blood components transfusion, ionotropic support and dialysis.

The parameters noted after ICU admission were patient outcome, review of mortality and areas of improvement. The purpose of review was to adopt more vigorous management strategies in critical care unit.

\section{RESULTS}

This observational study was conducted on 40 patients in present institute who were admitted in ICU between $1^{\text {st }}$ December 2016 to $28^{\text {th }}$ February 2019.

\section{Group 1}

Constituted 36 patients in whom intervention was done first followed by ICU management.

\section{Group 2}

Constituted 4 antenatal patients who were admitted to ICU for haemodynamic stabilization and thereafter obstetric intervention was done in two out of four patients.

All the more intervention was subject of decision at an appropriate time to facilitate early recovery out of the primary morbidity. The obstetrician's role is important although at a later stage of medical management. Since 
adequate data for group 2 was not available observations were pertained to group 1 .

Table 1: Demographic analysis.

\begin{tabular}{|l|l|l|}
\hline Parameters & No. of cases $(\mathbf{n = 3 6})$ & Percentage \\
\hline Age & 6 & 16.7 \\
\hline 20-30 years & 19 & 52.7 \\
\hline $\begin{array}{l}\text { >30 years } \\
\text { Gravidity }\end{array}$ & 11 & 30.6 \\
\hline Primigravida & 11 & \\
\hline G2 & 7 & 30.6 \\
\hline G3 & 9 & 19.4 \\
\hline G4 & 9 & 25.0 \\
\hline Booked/Referred & & 25.0 \\
\hline Booked & 10 & \\
\hline Referred & 26 & 27.8 \\
\hline Antenatal care & & 72.2 \\
\hline Given & 19 & \\
\hline Not given & 17 & 52.8 \\
\hline Gestational age & & 47.2 \\
\hline Upto 12 weeks & 3 & \\
\hline Upto 34 weeks & 8 & 8.3 \\
\hline Upto 36 weeks & 13 & 22.2 \\
\hline Term & 8 & 36.2 \\
\hline Pre-term & 4 & 22.2 \\
\hline
\end{tabular}

In present study most of the patients were in age group $20-30$ years $(52.7 \%)$ and gestational age up to 36 weeks $(36.2 \%)$.

Majority of cases were unbooked (74.3\%), 47.2\% cases did not receive antenatal care. It is an important risk factor for ICU admission (Table 1).

Table 2 shows that abnormal placentation, that is placenta previa $(n=8)$ and placenta accreta $(n=6)$ were the most common primary diagnosis at admission of obstetric cases requiring ICU admission, followed by cases of hypertensive diseases of pregnancy that is eclampsia $(n=6)$ and pre-eclampsia $(n=3)$.

The most common indication of ICU admissions was postpartum haemorrhage $(n=17)$.

The most common procedure was LSCS which was conducted in $55 \%$ of cases followed by laparotomy in $12.5 \%$ (Table 3 ).

Most common ICU intervention was blood transfusion $(81.19 \%)$ followed by mechanical ventilation which was done in $37.8 \%$ cases (Table 4 ).

Table 2: Indication of ICU admission/intervention done related to gestational age $(\mathrm{n}=40)$.

\begin{tabular}{|c|c|c|c|c|}
\hline Indication & Gestational age & Intervention & Indication of ICU shifting & No. of cases \\
\hline \multirow{2}{*}{ Eclampsia } & Upto 34 weeks & LSCS & $\mathrm{PPH}$ & 2 \\
\hline & Upto 36 weeks & LSCS & Eclampsia & 4 \\
\hline Pre-eclampsia & Upto 34 weeks & LSCS & Hypertensive crisis & 3 \\
\hline \multirow{3}{*}{ Placenta previa } & Upto 28 weeks & Hysterotomy & PPH & 2 \\
\hline & Upto 36 weeks & LSCS & PPH & 5 \\
\hline & Upto 34 weeks & LSCS & Eclampsia & 1 \\
\hline \multirow{3}{*}{ Placenta accreta } & \multirow{3}{*}{$\begin{array}{l}\text { Upto } 36 \text { weeks } \\
\text { to term }\end{array}$} & Peripartum hysterectomy & $\mathrm{PPH}$ & 4 \\
\hline & & LSCS & Asthma & 1 \\
\hline & & LSCS & Peripartum cardiomyopathy & 1 \\
\hline Anhydroamnios & Upto term & LSCS & PPH & 2 \\
\hline Acute pancreatitis & Upto term & LSCS & $\mathrm{PPH}$ & 1 \\
\hline Shock & Puerperium & ICU Management & Puerperal sepsis & 2 \\
\hline Ruptured uterus & Post abortion & Laparatomy & Haemodynamic instability & 2 \\
\hline Ruptured ectopic & $<12$ weeks & Laparotomy & Haemodynamic instability & 3 \\
\hline Breech & Upto term & LSCS & $\mathrm{PPH}$ & 1 \\
\hline Jaundice & Upto term & VD & Acute fatty liver of pregnancy & 1 \\
\hline $\begin{array}{l}\text { SLE with chronic } \\
\text { ITP }\end{array}$ & Upto term & $\begin{array}{l}\text { Vaginal delivery with PPH } \\
\text { (stitched vaginal tear) }\end{array}$ & Haemodynamic instability & 1 \\
\hline Ludwig angina & Upto term & LSCS & Tracheostomy & 1 \\
\hline \multirow{3}{*}{ Swine flu } & 36 weeks & Vaginal delivery (IUD) & Respiratory distress & 1 \\
\hline & 31 weeks & - & Respiratory distress & 1 \\
\hline & 36 weeks & - & Respiratory distress & 1 \\
\hline
\end{tabular}


Table 3: Obstetrical intervention undertaken $(n=40)$.

\begin{tabular}{|l|l|l|}
\hline No procedure & No. of cases & Percentage \\
\hline LSCS & 22 & 10.0 \\
\hline Cesarean hysterectomy & 4 & 55.0 \\
\hline Laparotomy & 5 & 10.0 \\
\hline Hysterectomy & 2 & 12.5 \\
\hline Vaginal delivery & 2 & 5.0 \\
\hline $\begin{array}{l}\text { Vaginal vault repair } \\
\text { (after colporrhexis) }\end{array}$ & 1 & 5.0 \\
\hline
\end{tabular}

Table 4: ICU interventions $(n=40)$.

\begin{tabular}{|l|l|l|}
\hline ICU intervention & No. of cases & Percentage \\
\hline Mechanical ventilator & 14 & 37.8 \\
\hline Blood products & 30 & 81.1 \\
\hline Ionotrophic & 10 & 27.0 \\
\hline Dialysis & 3 & 8.1 \\
\hline Anticonvulsants & 9 & 24.3 \\
\hline Anti hypertensive & 12 & 32.4 \\
\hline
\end{tabular}

In present study, it was seen in 2 cases multiorgan dysfunction was cause of mortality, one died due to hypertensive disorder of pregnancy and acute fatty liver of pregnancy was the cause in other case.

The remaining three died of peripartum cardiomyopathy, septic shock and respiratory distress due to swine flu (Table 5).

Table 5: Causes of maternal mortality $(n=40)$.

\begin{tabular}{|l|l|l|}
\hline $\begin{array}{l}\text { Cause of } \\
\text { mortality }\end{array}$ & Survivor & $\begin{array}{l}\text { Non } \\
\text { survivor }\end{array}$ \\
\hline $\begin{array}{l}\text { No mortality } \\
\begin{array}{l}\text { Hypertensive disorder } \\
\text { of pregnancy }\end{array}\end{array}$ & - & - \\
\hline $\begin{array}{l}\text { Multiorgan } \\
\text { dysfunction }\end{array}$ & - & 1 \\
\hline $\begin{array}{l}\text { Peripartum } \\
\text { cardiomyopathy }\end{array}$ & - & 2 \\
\hline $\begin{array}{l}\text { Acute fatty liver of } \\
\text { pregnancy }\end{array}$ & - & 1 \\
\hline $\begin{array}{l}\text { Septic shock } \\
\text { Swine flu }\end{array}$ & - & 1 \\
\hline Total & - & 1 \\
\hline
\end{tabular}

Table 6 shows that apart from community awareness which was required in all cases, some other areas of improvement were seen.

Antenatally, anaemia correction and ultrasound guided placental localization were the common areas of improvement seen in $20 \%$ of cases.

Early admission was needed in $17.5 \%$ of cases, blood and blood products arrangement in $12.5 \%$ of cases.
Table 6: Area of concern-obstetrician's perspective.

\begin{tabular}{|l|l|l|}
\hline Area of improvement & No. of cases & Percentage \\
\hline No factor & 1 & 2.5 \\
\hline Anaemia correction & 8 & 20.0 \\
\hline Placental localization & 8 & 20.0 \\
\hline Early admission & 7 & 17.5 \\
\hline High risk stratification & 6 & 15.0 \\
\hline Contraceptive advise & 1 & 2.5 \\
\hline Institutional delivery & 4 & 10.0 \\
\hline Blood arrangement & 5 & 12.5 \\
\hline Total & 40 & 100.0 \\
\hline
\end{tabular}

\section{DISCUSSION}

Obstetric medicine is unique and complicated. It is different from general medicine because of various physiological changes occurring in pregnancy. The obstetric patients are more prone to ICU admission especially if associated complicating factors are present. In obstetric complications like haemorrhage and hypertensive disorders, disseminated intravascular coagulation develops very rapidly. The threshold for ventilator support is also low in pregnancy.

In present study rate of ICU admissions from December 2016 to February 2019 was $1.1 \%$ of all deliveries. Total number of deliveries in this time period were 3607 and there were 40 admissions in ICU. Al Suleiman et al, reported a study in 2006 on obstetric admission to ICU12 years review with admission rate of $0.22 \% .^{6}$ Mabie WC and Sibai BM reported a study with admission rate of $0.9 \% .^{7}$ The rate in present study is higher than these studies because most of ICU cases included in present study were referred to present institute for tertiary care.

The commonest age group in present study was between 20-30 years $(52.7 \%)$. Study done by Rochat et al, showed that $72 \%$ of cases belonged to age group of 21-30 years. ${ }^{8}$

The commonest gestation age in present study was patients upto 36 weeks gestation accounting for $36.2 \%$ and patients with term pregnancy were $22.2 \%$. It indicates that complications are more common at term and around the time of delivery. Bhadade $\mathrm{R}$ et al reported a study which stated that maximum admissions requiring ICU were in $3^{\text {rd }}$ trimester $(41 \%)$ and in puerperium $(33.6 \%) .{ }^{9}$ It was also observed that $72.2 \%$ cases were referred from outside and $47.2 \%$ were unsupervised with no antenatal care. A study done by Jain $\mathrm{S}$ et al depicted that in referred patients and delay at an intermediary facility doubled the risk. ${ }^{10}$ There is also need to educate junior doctors and nurses in periphery to identify high risk cases and their timely referral.

The most common intervention done during present study was LSCS (55\%). Keizer JL et al reported a study on obstetric ICU admission that had a rate of $50.7 \%$ of LSCS as surgical intervention in ICU patients. ${ }^{11}$ 
Zwartts JJ et al reported a study that had a rate of $52.9 \%$ of LSCS as surgical intervention in ICU patients. ${ }^{12}$ The rates of both the studies are comparable with present study. Cesarean delivery, especially in presence of obstetric and medical comorbidities can be a potential risk factor for ICU admission.

It was seen that postpartum haemorrhage $(n=17)(42.5 \%)$ was commonest condition that required ICU admission followed by hypertensive disorders of pregnancy $(n=9)$ (22.5\%). Study by Rathod AT, Malini KV reported obstetric haemorrhages as the commonest condition for ICU admission accounting for $(44.05 \%) .{ }^{13}$ A study reported by Zeemen GC et al revealed hypertensive disorders as main indication for ICU admission. ${ }^{14}$

In present study, it was found that blood and blood products transfusion was the main ICU intervention done in $81.1 \%$ of patients, followed by ventilator support in $37.8 \%$ of patients. Rathod AT, Malini KV also reported blood and blood products were main stay for ICU intervention.

There were 7 maternal deaths in present study which accounts for $17.5 \%$ of obstetric patients admitted in ICU. Multiorgan dysfunction was cause of death in two patients and one case each was of hypertensive disorder, peripartum cardiomyopathy, septic shock and acute fatty liver of pregnancy. Three patients were admitted with diagnosis of swine flu. Out of them one expired due to respiratory failure, second left against medical advise, third patient, admitted with IUD at 36 weeks gestation was first stabilized haemodynamically and then induced for labour and was delivered vaginally. Vasquez DN et al reported maternal mortality of $11 \%$ with multiorgan dysfunction syndrome (44\%) as main cause. ${ }^{15}$

The risk reduction strategies identified and analyzed by present study are:

1. Optimizing antenatal/intranatal management.

2. Rational use of blood transfusion and blood components.

3. Surgical v/s conservative management - appropriate decision at appropriate time.

4. Identification of risk factors and timely referral to tertiary care centre.

5. Intensive ICU monitoring and optimizing intervention to reduce risk of sepsis, anaemia, multiorgan failure.

6. Management of medical/surgical comorbidities with team work.

\section{CONCLUSION}

There is need for training in emergency obstetrics, so that complications can be managed right at the time of occurrence. Close coordination among intensivists, obstetricians, anaesthesiologists is required. During transportation of the critically ill obstetric patients to tertiary care ICU, maternal parameters have to be monitored. A well secured intravenous access, availability of emergency drugs, equipments for intubation and mechanical ventilation are requirement for safe transportation. There is also need to train obstetricians in critical care to do justice to these critically ill patients.

\section{ACKNOWLEDGMENTS}

Authors would like to thank Department of Obstetrics and Gynecology of SGRDUHS, Amritsar.

Funding: No funding sources

Conflict of interest: None declared

Ethical approval: The study was approved by the Institutional Ethics Committee

\section{REFERENCES}

1. Harmer M. Editorial maternal mortality-is it still relevant?. Anaesthesia. 1997;52(2):99-100.

2. Wanderer JP, Leffert LR, Mhyre JM, Kuklina EV, Callaghan WM, Bateman BT. Epidemiology of obstetric-related intensive care unit admissions in Maryland: 1999-2008. Crit Care Med. 2013;41(8):1844.

3. Bandeira AR, Rezende CA, Reis ZS, Barbosa AR, Peret FJ, Cabral AC. Epidemiologic profile, survival and maternal prognosis factors among women at an obstetric intensive care unit. Int $\mathbf{J}$ Gynecol Obstet. 2014;124(1):63-6.

4. Sultan P, Arulkumaran N, Rhodes A. Provision of critical care services for the obstetric population. Best Pract Res Clin Obstet Gynecol. 2013;27(6):8039.

5. Baskett TF, O'Connell CM. Maternal critical care in obstetrics. J Obstet Gynecol Can. 2009;31(3):218-21.

6. Al-Suleiman SA, Qutub HO, Rahman J, Rahman MS. Obstetric admissions to the intensive care unit: a 12-year review. Arch Gynecol Obstet. 2006;274(1):4-8.

7. Mabie WC, Sibai BM. Treatment in an obstetric intensive care unit. Am J Obstet Gynecol. 1990;162(1):1-4.

8. Rochat RW, Koonin LM, Atrash HK, Jewett JF. Maternal mortality in United States. Obstet Gynecol. 1988;72(1):91-7.

9. Bhadade R, de'Souza R, More A, Harde M. Maternal outcomes in critically ill obstetrics patients: A unique challenge. Indian J Crit Care Med. 2012;16(1):8-16.

10. Jain S, Guleria K, Vaid NB, Suneja A, Ahuja S. Predictors and outcome of obstetric admissions to intensive care unit: A comparative study. Indian $\mathbf{J}$ Public Health. 2016;60(2):159-63.

11. Keizer JL, Zwart JJ, Meerman RH, Harinck BI, Feuth HD, van Roosmalen J. Obstetric intensive care admissions: a 12-year review in a tertiary care centre. Europ J Obstet Gynecol Reprod Biol. 2006;128(12):152-6. 
12. Zwart JJ, Dupuis JR, Richters A, Öry F, van Roosmalen J. Obstetric intensive care unit admission: a 2-year nationwide population-based cohort study. Inten Care Med. 2010;36(2):256-63.

13. Rathod AT, Malini KV. Study of obstetric admissions to the Intensive Care Unit of a Tertiary Care Hospital. J Obstet Gynecol India. 2016;66(1):12-7.

14. Zeeman GG, Wendel GD Jr, Cunningham FG. A blueprint for obstetric critical care. Am J Obstet Gynecol. 2003;188(2):532-6.
15. Vasquez DN, Estenssoro E, Canales HS, Reina R, Saenz MG, Neves AV, Toro MA, Loudet CI. Clinical characteristics and outcomes of obstetric patients requiring ICU admission. Chest. 2007;131(3):718-24.

Cite this article as: Preetkamal, Bala R, Kaur S, Nagpal M. Obstetrics ICU admissions: learning objectives. Int J Reprod Contracept Obstet Gynecol 2019;8:1294-9. 